\title{
O DISCURSO SOBRE A REDUÇÃO DA MAIORIDADE PENAL EM DUELOS DE MCS
}

\author{
Valmir Joaquim da Silva Junior ${ }^{1}$
}

RESUMO: Esta pesquisa tem por objetivo analisar como o discurso sobre a redução da maioridade penal é construído por MCs, codinome para Mestre de Cerimônias, nas batalhas de rimas das quais participam, observando a elaboração e a organização dos temas e dos discursos suscitados por eles em suas rimas improvisadas. Para realizar a análise, tomamos por base os pressupostos da Análise Crítica do Discurso (ACD) de Norman Fairclough (1992, 2003), perspectiva em que o discurso é entendido tanto como modo de ação quanto como modo de representação, sendo considerado, ainda, como uma forma de prática social. Nesse ínterim, o discurso é o lugar para observar como estruturas linguísticas podem reproduzir ou contestar aspectos do mundo. Selecionamos quatro batalhas, disponibilizadas na plataforma de vídeo Youtube, pelo canal Família de Rua, cuja discussão se deu acerca da maioridade penal. A categoria de duelo que estabelece um tema para disputas é chamada de "conhecimento", uma vez que o objetivo consiste nos participantes exibirem aquilo que sabem a respeito de determinado assunto previamente definido. Após a transcrição das batalhas, partiu-se para a identificação dos discursos mobilizados pelos MCs para desenvolver suas ideias. Os resultados da pesquisa mostraram como determinados discursos foram articulados para construir um discurso maior que sustenta uma posição contrária à redução da maioridade penal. Entre os temas evocados nas batalhas estão a mídia, a esfera política, a escola etc. Através dos discursos baseados nos referidos temas, pudemos perceber que os MCs têm consciência do porquê são contrários à diminuição da maioridade, não se configurando como um discurso vazio, além de apontarem um caminho para uma mudança social da qual eles sejam agentes participativos.

Palavras-chave: Maioridade Penal. Discurso. MCs. ACD.

ABSTRACT: This research aims to analyze how the discourse on reducing the age of criminal responsibility is constructed by MCs, codenamed for Master of Ceremonies, in the rhyme battles in which they participate, observing the elaboration and organization of the themes and speeches raised by them in their improvised rhymes. In order to carry out the analysis, we take as a basis the assumptions of Critical Discourse Analysis (ACD) by Norman Fairclough $(1992,2003)$, a perspective in which discourse is understood both as a mode of action and as a mode of representation, being considered, still, as a form of social practice. In the meantime, discourse is the place to observe how linguistic structures can

\footnotetext{
${ }^{\mathrm{I}}$ Mestre em Linguística pela UFPE. Atualmente doutorando em Linguística na mesma instituição. Bolsista
} CAPES/DS. 
reproduce or challenge aspects of the world. We selected four battles, available on the Youtube video platform, through the Família de Rua channel, whose discussion took place about the age of criminal responsibility. The category of duel that establishes a theme for disputes is called "knowledge", since the objective is for the participants to show what they know about a previously defined subject. After the transcription of the battles, we started to identify the speeches mobilized by the MCs to develop their ideas. The results of the research showed how certain speeches were articulated to build a larger discourse that supports a position contrary to reducing the age of criminal responsibility. Among the themes evoked in the battles are the media, the political sphere, the school etc. Through speeches based on these themes, we could see that the MCs are aware of why they are opposed to the decrease in adulthood, not being configured as an empty discourse, in addition to pointing out a path for social change in which they are participatory agents.

Keywords: Criminal Majority. Discourse. MCs. ACD.

\section{INTRODUÇÃO}

Geralmente, é comum termos acessos a determinados discursos por meio, principalmente, da mídia e dos mais variados meios de comunicação impressos, audiovisuais e digitais. Analisar como se dá o contexto de produção e a materialização desses discursos têm sido uma prática recorrente nos estudos das ciências sociais e da linguagem. Essa forma de investigar um discurso e as vozes que o constituem, analisando jornais e revista, por exemplo, é apenas uma das maneiras possíveis de conhecê-lo. Em contrapartida, alguns grupos sociais não têm suas ideias tão difundidas quanto os detentores da produção e da divulgação midiática; suas vozes não reverberam, muito menos são tão ouvidas quanto a de certos grupos e setores da sociedade.

Nesse ínterim, a tarefa deste trabalho é estudar um dos temas que mais têm suscitado debates no século XXI: a redução da maioridade penal. Faremos isso através dos discursos dos MCs (Mestre de Cerimônia), quando estes estão participando de batalhas de rima. Tais duelos dizem respeito a um gênero da esfera oral, no qual dois ou mais MCs disputam a preferência do público e/ou de um júri; sua realização não existe fora do texto falado. O gênero em questão ocorre numa situação particular de realização, dizendo respeito a interações parcialmente programadas, uma espécie de debate discursivo, por meio de rimas, no qual avaliações, posicionamentos e julgamentos dos mais diversos temas são realizados a todo momento. Desse modo, nosso objetivo é analisar como o discurso sobre a redução da maioridade penal é construído pelos MCs durante as batalhas, observando como esse discurso articula-se a outros, seja para ser corroborado seja para se apresentar como alternativa. 
O discurso hegemônico e midiatizado sobre os principais temas da sociedade, por vezes, é tomado como único. Segundo Fairclough (2016), um dos objetivos da Análise Crítica do Discurso, doravante ACD, perspectiva teórica adotada neste trabalho, é dar voz a quem não tem seus discursos corroborados pela sociedade. Nesse sentido, investigar o discurso dos MCs sobre um tema que lhes parece tão importante pode fazer com que percebamos novas visões e ideias a respeito da temática investigada. Estes jovens, ligados ao universo do rap e do hip-hop, têm visões particulares do assunto aqui discutido, que, em grande maioria, diferem das ideias socializadas pela/na mídia hegemônica ou por outras instâncias. A discussão sobre a maioridade penal parece não ouvir o alvo dessa ação: os jovens. Uma pesquisa no banco de dados do site "Periódicos Capes/Mec" mostrou que esse assunto é majoritariamente tratado sob algumas óticas, tais como a midiática (cf. BUDÓ, 2015) e a política (cf. DOTTO e MORAIS, 2018); mas raramente a visão dos adolescentes, alvo do debate, é levada em conta. Assim, esperamos perceber como o discurso dos MCs, parte deles menores de idade, legitimam ou rejeitam discursos hegemônicos sobre a redução da maioridade penal.

O artigo está estruturando da seguinte forma: depois desta introdução, abordaremos de onde partimos em relação aos pressupostos teóricos; em seguida, realizamos uma breve discussão acerca da maioridade penal; seguimos com a indicação da metodologia; posteriormente, apresentamos a anáilise do corpus selecionado; por fim, as considerações finais.

\section{Fundamentação teórica}

Subjacente a ideia foucaultiana de linguagem como espaço de luta hegemônica, Fairclough e sua abordagem da ADC, nomeada de Teoria Social do Discurso, lançam mão de uma perspectiva a qual entendem o discurso como linguagem em uso e como parte irredutível da vida social que está conectada a outros elementos sociais. Dessa forma, ao tomar discurso como uso de linguagem, Fairclough (2016) o considera como forma de prática social e não como atividade individual ou como reflexo de variáveis determinadas. Por isso, o autor apresenta duas características do discurso: a) é um modo de ação; b) é modo de representação. A primeira diz respeito à possibilidade de o discurso agir sobre as pessoas e sobre as estruturas sociais; a segunda, por sua vez, refere-se à propriedade do discurso como representação das coisas do mundo. 
Isso significa que esta teoria postula tanto um direcionamento social quanto um linguístico-textual. Empreender uma investigação ancorada nessa vertente da ACD implica tomar a relação entre discurso e sociedade como dialética, um agindo sobre o outro e ambos constituindo-se mutuamente. O discurso, baseado em um direcionamento funcionalista, seria o lugar para visualizar como estruturas linguísticas são usadas para representar eventos, relações sociais e reprodução ou contestação de hegemonias, entre outras coisas. Nessa perspectiva, ao mesmo tempo que o discurso é moldado e restringido pelas estruturas sociais, contribui para constituir as estruturas sociais que o moldam e o restringem (FAIRCLOUGH, 2016). É dessa tensão entre discurso e estruturas sociais que o mundo ganha significação, segundo o autor "o discurso é uma prática, não apenas de representação do mundo, mas de significação do mundo, constituindo e construindo o mundo em significado". Por isso, as práticas discursivas tanto servem para reproduzir a sociedade quanto para tentar transformá-la.

É desse jogo entre discurso e estrutura social que se delineiam as hegemonias e as lutas de poder. Fairclough (2016), resgatando as discussões sobre hegemonia de Gramsci, aponta a que a hegemonia diz respeito a um processo de dominação velada de um grupo sobre os outros baseada mais no consenso do que na força. O poder hegemônico, assim, se sustenta através de alianças de forças sociais sobre a sociedade. Para o autor as lutas hegemônicas têm dimensões ideológicas e os processos de dominação decorrem da naturalização de representações sociais ocorridas nas práticas discursivas. Isso significa que as hegemonias são produzidas, reproduzidas, contestadas e transformadas no discurso.

Podemos dizer que a análise das hegemonias no discurso pode localizar e caracterizar tanto práticas sociais, apontando como se dão as relações de poder, se elas reproduzem, reestruturam ou desafiam as hegemonias existentes; quanto práticas discursivas como modo de luta hegemônica que reproduz, reestrutura e contesta discursos. As práticas discursivas podem naturalizar ideologias - entendidas como crenças e conhecimentos partilhados -, moldando os papéis sociais e as relações que sujeitos estabelecem quando participam dessas práticas.

Se são os sujeitos que possibilitam a disseminação de ideologias e consequentemente o estabelecimento de hegemonias, é também o sujeito que pode interferir nessa realidade. Existe, então, uma possibilidade de desarticulação e rearticulação das forças sociais através da agência humana. São os indivíduos, nas práticas sociais e discursivas, que podem viabilizar transformações nas estruturas sociais. 
Para operacionalizar com a ADC a partir desse entendimento, Fairclough (2003, 2016) apresenta instrumentos de análise que se ligam a propriedades da crítica social ora pertencem ao campo textual e linguístico. A orientação textual da ADC encontra na Linguística Sistêmico-Funcional sua base de apoio. Além de se apropriar dos pressupostos da teoria hallidayana, Fairclough (2003) realiza desdobramentos baseados em Halliday de sua própria teoria. Aqui trabalharemos com os pressupostos mais recentes de Fairclough em relação à LSF. Halliday (2014) aponta que agimos na língua realizando três funções principais: a ideacional, responsável por representar o mundo; a interpessoal, que tem a ver com a relação entre os interactantes; e textual, que se preocupa com a organização textual. A essas funções ele dá o nome de macro ou metafunção.

Em seus estudos mais recentes, Fairclough (2003) sugere no lugar das funções da linguagem, três tipos de significados, ligando-os aos conceitos de gênero, discurso e estilo. O discurso, então, figura de três maneiras nas práticas sociais: modos de agir, de representar e de ser. Há uma correspondência entre esses modos de figurar e os conceitos trazidos anteriormente, pois o autor aponta que gêneros, discursos e estilos são, respectivamente, modos de agir, representar e identificar relativamente estáveis. Dessas associações nascem os significados acional, representacional e identificacional.

A análise será baseada, especialmente, nas categorias relativas ao significado representacional, que tem a ver com o discurso como modo de representação dos aspectos do mundo, abarcando processos como a interdiscursividade, conceito que diz respeito à relação e à articulação entre os discursos. Analisar textos em uma perspectiva interdiscursiva implica identificar a articulação dos discursos e o modo como eles são articulados. Dessa forma, é possível visualizar não só discursos contrários, discursos que se chocam; mas também a relação entre determinados discursos que articulam a construção de um discurso maior. Para Fairclough (2003, p. 134) "the relationships between different discourses are one element of the relationships between different people - they may complement one another, compete with one another, one can dominate others, and so forth”. Essas percepções de dominação se dão no discurso e é agindo discursivamente que há possibilidade de mudanças.

Outra categoria utilizada na análise é nomeada por Fairclough (2016) de significado de palavras, que aponta como o sentido das palavras se inserem em contextos ideológicos mais amplos. Determinadas escolhas lexicais têm forte ligação com o discurso que se tenta legitimar ou rechaçar. A opção por uma palavra ou outra, além de não ser aleatória, liga-se 
a questões contextuais e de sentido muito particulares de determinadas práticas sociais e ideologias.

\section{Uma breve discussão sobre a maioridade penal}

Podemos encontrar a regulamentação da maioridade penal no Brasil em três documentos oficiais: Constituição Federal, no artigo 228, o qual postula-se serem penalmente inimputáveis os menores de dezoito anos; entendimento igual também é encontrado no Código Penal, em artigo 27 , informando que os menores de de idade são penalmente inimputáveis e ficam sujeitos à legislação especial; a mesma preconização ocorre no artigo IO4 do ECA (Estatuto da Criança e do Adolescente). Os três escritos legais não deixam dúvidas sobre o caráter de imputabilidade que recai sobre o menor de 18 anos. O ECA, artigo II2, dispõe acerca das medidas socio-educativas aplicadas ao adolescente que comete ato infracional, entre elas estão: I - advertência; II - obrigação de reparar o dano; III prestação de serviços à comunidade; IV - liberdade assistida; V - inserção em regime de semi-liberdade; VI - internação em estabelecimento educacional; entre outras deliberações previstas no art. IOI, I a VI.

Não obstante essa regulamentação, há uma parcela da população que não concorda com a tais medidas, julgando-as brandas demais. Aliado a isso, há também a crescente sensação de insegurança sentida por boa parte da população brasileira. Como consequência desses dois pontos, desde 1993, diversos projetos de emendas constitucionais objetivando a redução da maioridade penal foram encaminhados ao congresso. Algumas dessas PECs propõem diminuições que chegam até os 12 anos de idade, como é o caso da PEC 345, proposto em 2004 pelo então deputado Silas Brasileiro, do antigo PMDB, atual MDB. Campos (2009) apontou que até 2007 quase trinta propostas de emenda constitucional haviam sido apresentadas ao Congresso Nacional. Segundo o autor, a maioria dos projetos estipulam a idade de 16 anos como sendo a mais apropriada para que o adolescente deixe de ser inimputável. O argumento do grupo que se mostra favorável a redução da maioridade gira em torno de apontar que os adolescentes têm maturidade intelectual e emocional suficiente, podendo, assim, ser responsabilizados por seus atos. Entre os argumentos das pessoas contrárias à diminuição estão a ineficiência do sistema prisional brasileiro em cumprir com sua função de ressocializar os indivíduos e o fato de os delitos realizados por menores de idade correspondem a menos de I0\% do total (LINS, FILHO \& OLIVEIRA, 2016). 
Para Soares (2007) o debate sobre esse tema é praticamente todo baseado em achismos. Podemos dizer, então, que as perspectivas assumidas pelas pessoas se baseiam muito mais em vieses ideológicos do que em estudos e dados embasando suas posições. Campos (2009) analisa como a mídia e casos isolados de crimes cometidos por menores serviram de influência para a elaboração de diversos projetos de emendas constitucionais. Percebendo a falta de produções técnicas a respeito do assunto, Lins, Filho e Oliveira (2016) cruzam dados de diversas pesquisas realizadas no mundo todo procurando encontrar se há correlação entre a maioridade penal e os índices de violência. Os autores chegam à conclusão de que quanto maior a idade penal menor o índice de criminalidade, não havendo, portanto, uma relação direta entre uma maioridade menor e um baixo índice de crimes.

Para além da não atenção que os estudos correlacionando variáveis recebe, está o poder e a voz de determinados agentes e instituições sociais. Encontramos tanto trabalhos que tratam da visão dos parlamentares e de questões inerentemente legislativas quanto pesquisas que reportam como a mídia aborda o assunto. Ou seja, aparentemente se analisa e se dá importância apenas para como forças sociais hegemônicas, a exemplo da política e da mídia, lidam com o tema.

\section{Corpus e metodologia}

O corpus desta pesquisa é composto a partir das transcrições de textos produzidos pelos MCs durante as disputas de rimas. Geralmente, essas batalhas são de tema livre, porém há uma modalidade de disputa chamada "conhecimento", na qual os MCs duelam sobre um tema que lhes é informado pouco antes de os duelos começarem. Os duelos analisados são organizados, gravados e disponibilizados no Youtube pelo coletivo Família de Rua, de Belo Horizonte, lugar onde ocorrem as batalhas. Mas salientamos que essas disputas de rimas acontecem no Brasil todo, sendo possível encontrar uma grande varidade de batalhas nas plataformas digitais. Nosso material de análise corresponde a cinco produções dos MCs, cujo tema é redução da maioridade penal. Nessa batalha específica participaram oito MCs que produziram treze textos. Acreditamos que os cinco textos por nós escolhidos condensam os discursos desses jovens sobre o tema tratado.

Após a transcrição, houve a identificação dos discursos trazidos pelos MCs durante as batalhas e a investigação de como esses discursos foram articulados para defender e demonstrar um ponto de vista e um discurso mais amplo. Cada texto foi analisado 
primeiro individualmente, procurando observar as particularidades de cada produção. Após a identificação dos discursos suscitados pelo tema maioridade penal, escolhemos os trechos representativos de cada texto que seriam apresentados e discutidos no corpo do trabalho. O leitor pode ter acesso às transcrições que foram realizadas para essa pesquisa acessando https://docs.google.com/document/d/ı2bxfqviPqaVvoG_cjBjRvvD8brl_kLiY/edit?usp=s haring\&ouid=109540501106156398022\& $\mathrm{rtpof}=$ true $\& \mathrm{sd}=$ true, bem como o respectivo link para visualização dos vídeos de onde os textos foram coletados.

\section{Análise dos dados}

Neste trabalho, defendo a tese de que as falas dos MCs caminham juntas para construir um discurso de resistência que se opõe tanto à redução da maioridade penal quanto ao discurso hegemônico sobre o tema, que tende a tomar a redução como uma importante medida no combate à violência. Para a construção desse discurso de oposição, eles suscitam temas como educação, corrupção, televisão, o rap etc. A análise foi realizada justamente através da identificação dos discursos atrelados a esses temas supracitados e de como esses rappers articulam esses discursos, o qual chamamos de discursos-suporte, na intenção de corroborar com o macrodiscurso de resistência. Dessa maneira, podemos dizer que esses discursos, atrelados a assuntos específicos, funcionaram como discurso-suporte, pois corroboraram com um discurso mais amplo de negação à redução. Além dessa análise baseada na interdiscursividade, também investigamos, baseado na categoria significado de palavras, como o termo "menor/menorzin" diz respeito não a indivíduos menores de idade pura e simplesmente, mas sim àquele que está em situação desfavorável. Nesse contexto, menor significa o jovem morador de comunidade com poucas oportunidades, perfil muito semelhança aos dos Mcs que se engajam nas batalhas.

\section{O macrodiscurso: A oposição à redução}

Em todos os textos analisados, os MCs se mostraram explicitamente contrários à redução da maioridade penal. Essa tomada de posição já os coloca ideologicamente em choque com o grupo de pessoas que apoia a diminuição da idade penal, isso implica, então, a existência de pelo menos dois grupos de pessoas que compreendem e interpretam uma realidade específica do lugar onde vivem de formas diferentes. E é justamente no discurso 
que essa realidade é (re)construída a todo momento. Seja falando através de uma posição marcadamente individual, como nos exemplos abaixo (I) e (3); seja se colocando enquanto porta-voz de um grupo de pessoas, como no excerto (2), em seus discursos eles demonstram contrariedade a tal proposta que defende a redução da maioridade penal. Vejamos os trechos abaixo.

I. eu digo não à redução, esse é meu termo cadeia sempre dá lucro, mas pros cuzões do governo eles querem dinheiro em cima dos meus menor

2. Minas Gerais tem que progredir e não regredir vamos pensar juntos que assim a gente vai evoluir é foda, irmão, tá nessa situação Minas diz não à porra da redução!

3. governo safado, político safado eu digo não à redução no meu improvisado

4. Redução não é a solução

Afinal salvação só na educação

Observamos em (I) a utilização da palavra menor se referindo, como já foi adiantado, não a todos os menores de idade, mas àqueles que estão em uma realidade específica. São as crianças e adolescentes circunscritos em uma situação cuja falta de perspectiva de vida domina. Percebemos, então, que nas batalhas essa palavra carrega uma carga ideológica que traz consigo toda uma gama de reflexões, evidenciando como uma determinada realidade é aprendida.

A abordagem contrária de forma tão categórica em relação à diminuição da maioridade penal se explica à medida em que vai se desenhando os motivos pelos quais essa posição é tomada. As seções que se seguem apresentam os discursos-suportes que, de alguma forma, embasam o discurso apresentado nesta seção.

\section{Educação: salvação ou dominação}

Trazer o tema educação para discorrer sobre a questão da maioridade penal significa que os MCs entendem que essa discussão suscita um viés social e político, não podendo ficar baseado apenas em questões de ordem jurídica e/ou legislativa. Os MCs, jovens negros, a maioria morador de comunidade, compreendem o papel que a educação poderia ter na luta contra a derrocada dos menores para o mundo crime. Nesse caso, então, 
a educação é entendida como instrumento que possibilitaria uma mudança de realidade.

Observe os trechos abaixo:

5. os caras fala só em detenção igual já falei antes... eu falo educação

é minha educação, pra mim e pra meus irmãos

6. não tem direito à moradia nem a estudo

e depois cresce e querem cobrar dos caras um conteúdo?

eles fazem Enem

mas não tá tudo bem

na favela o que se aprende é só roubar e fazer neném

7. eu quero uma escola de qualidade melhor

ninguém tem escola, isso que não é câo

na cadeia, nunca vai faltar um professor

pra ensinar a matar, pra ensinar a roubar

Por falta de investimento devido na educação, abre-se a possibilidade de entrada dos jovens no mundo do crime. Nos exemplos (6) e (7), os Mcs deixam claro sua percepção em relação à ausência de práticas escolares de boa qualidade. Fica claro, desse jeito, que educação e criminalidade caminham juntas, e que a falta da primeira está diretamente relacionada com o aumento da segunda.

O discurso sobre a educação ainda segue outro caminho, além de recorrer à precariedade do sistema educacional, houve uma avaliação sobre a instituição escola e a configuração de seu espaço. No trecho (8), abaixo, o MC discorre sobre o carácter autoritário e dominador da escola, tecendo uma crítica a respeito do quanto esse ambiente pode parecer uma prisão. Não basta ter escolas, elas têm que entender a realidade e as necessidades dos alunos. A seguir, veja o exemplo:

8. é 332012 o número dessa pec que vai valer só pros rechaçados pelo mec porque, irmão, não tem um livro decente isso daí já é suficiente porque a gente não vê um futuro olha a sala de aula, já é uma detenção sem muro

Vemos, então, a articulação de dois discursos sobre educação que caminham juntos para mostrar o lado opositivo dos mcs a respeito da redução. Os "rechaçados" pelo MEC aos quais o Mc se refere estabelece uma relação semântica com o termo "menor", 
apresentado acima, pois ambos dizem respeito aos menores de idade socialmente excluídos. Desta forma, os discursos dos MCs, embora por caminhos diferentes, tratam dos mesmos temas.

\section{Ambição e descaso dos políticos}

Responsáveis pelas propostas de diminuição da idade penal, políticos são vistos pelos MCs como indivíduos pertencentes a uma classe que não se importa com ou trabalham para a realização de políticas públicas com o objetivo de melhorar a vida das pessoas. É recorrente a ideia de que a redução da maioridade penal e a construção de novos presídios seriam maneiras de não combater o problema da inserção dos jovens no crime de forma correta e eficaz, mas de negá-las e ocultá-las. Além disso, há a percepção de que a política funciona como instrumento de ganho financeiro. Assim, à figura do político, além do descaso, está associada a ideia de ambição. Vejamos os trechos abaixo.

9. isso daí, irmão, só alimenta o Estado

e aquele bando de governante retardado

é isso, irmão, ignorante

vai reduzir uma prioridade, reduz o número de governantes

Io. cadeia sempre dá lucro, mas pros cuzões do governo

eles querem dinheiro em cima dos meus menor

II. Afinal salvação só na educação

e eles vai tentar criar mais prisão

porque eles não querem ajudar os irmãos

Em (9) e (го), as palavras alimenta e lucro, relacionadas ao Estado e ao governo, respectivamente, conectam-se à ideia da classe política como oportunista. A argumentação é baseada na compreensão de que a redução da maioridade não pode ser levada a sério se seus propositores não pensam, de fato, nas pessoas, como mostra o exemplo (II); mas sim em dinheiro e em maquiar o problema. As medidas propostas por eles, como é o caso da redução, seriam imediatistas e esconderiam a complexidade da questão, não pensando no problema em sua gênese.

O discurso-suporte apresentado nesta secão tenta evidenciar que existe um direcionamento por partes dos políticos que tenta solucionar os problemas da sociedade através do punitivismo. O encarceramento é entendido como castigo para quem é negro, 
pobre e morador de comunidades. A próxima sessão está diretamente ligada com as questões apresentadas neste tópico.

\section{A TV: recortes e falseamento}

Outro importante tema abordado pelos MCs em seus textos orais diz respeito à televisão. Eles advogam que a mídia televisiva, representando os veículos de impressa de forma geral, opera construindo uma imagem negativa de moradores de comunidades e consequentemente dos menores de idade que vivem nesses lugares. Essa associaçaõ entre criminalidade e jovens moradores de favelas realizadas pela TV, na visão dos MCs, podem aumentar o entendimento de que a situação da violência seria amenizada com o encarceramento desses adolescentes. Nos excertos (14) e (I5), podemos ver como os Mcs percebem o modo de a TV representar as pessoas da e o que passa na favela.

I2. é tipo assim... essa é que é a proposta:

quando morre um preto na favela na televisão não mostra

eles só mostram quando um preto ta assaltando

mesmo sendo menor eles tão só criticando

e quer falar da nossa cultura?

13. o,oI\% dos menorzin que eu conheço tá no movimento do crime

e é esses que eu quero logo cuidar e trazer pro meu time

e $36 \%$ são assassinato

eles não mostram esses relatos

lá na televisão é tudo ilusão

Por vezes, os MCs usam o pronome de terceira pessoa do plural "eles", tanto nesta quanto na seção anterior, referindo-se a todas aqueles que parecem contribuir seja para a manutenção de um discurso contra o negro, seja para sustentar a ideia de que a redução é necessária. Dessa forma, para esses jovens o discurso da mídia e o dos políticos formam, assim, uma aliança discursiva hegemônica responsável por fomentar uma ideologia.

Esse entendimento que os Mcs apontaram nesta e na sessão anterior remonta ao trabalho de Campos (2009), nele o autor mostra que a mídia, sobretudo a TV, teve um importante papel no aumento de PECs apresentadas ao congresso por parte dos parlamentares tendo como foco a diminuição da maioridade penal. Dessa forma, vemos que os Mcs conseguem ter uma visão bastante holística da situação a qual estão inseridos.

\section{Um movimento de resistência}


Marcando mais uma vez suas posições, os MCs advogam que o movimento do qual eles participam, sendo compreendido, neste caso, pelo rap e pelos duelos, é capaz de instrumentalizá-los como agentes de mudança do mundo que os cercam. A (r)evolução acontece quando há união, quando há pensamento de grupo e não baseada em desejos individuais. Dessa maneira, podemos perceber que, apesar de não realizarem uma comparação, os MCs se colocam como muito mais úteis do que os políticos. Assim, esse discurso está interconectado aos discursos da seções anteriores, funcionando como uma resposta a eles. Observe nos exemplos abaixo:

14. e quem sabe a união vai fazer a revolução

a união faz a força sim

e por isso mesmo que o frestyle nunca vai ser ruim

15. por isso que o governo ta falando do alheio

e nessa patifaria eu que vou por um freio

eu, você e todo mundo que tá aqui junto no momento

porque nós sim que somos o movimento

16. o,oı\% dos menorzin que eu conheço tá no movimento do crime e é esses que eu quero logo cuidar e trazer pro meu time

Nos trechos acima, vemos em (I6) e (17), o discurso de união propapado pelo hiphop, configurando-se, assim, como um movimento coletivo de resistência. A chamada para a soma de forças nos exemplos supracitados é mais uma ação que se liga à posição de contrariedade em relação à diminuição da maioridade penal. É se unindo que mudanças acontecem. Nesse ínterim, o hip-hop preencheria uma lacuna deixada pelos governantes, sendo um movimento muito mais coeso, organizado, que entende as necessidades dos seus iguais e que tem o poder de realizar mudanças sociais. Os Mcs, assim, poderiam ser responsáveis pela promoção de mudanças.

\section{CONSIDERAÇÕES FINAIS}

Quando escolhemos tratar da maioridade penal pelo viés dos jovens participantes dos duelos de Mcs, já tínhamos ideia de que eles se mostrariam contrários a tal proposta. Os resultados da pesquisa foram além e mostraram que os MCs têm consciência do porquê dessa decisão, não se configurando como um discurso vazio, além de apontarem um caminho para a mudança social a qual eles sejam agentes (particip)ativos. 
Vimos que eles constroem seus discursos como resposta a um discurso hegemônico do qual participam a mídia e a classe política. Para tanto, invocam o descaso deste último com a educação e o tratamento que o primeiro dá aos jovens negros. Mídia e tv agem juntas para reproduzir um discurso hegemônico baseado na sensação de insegurança das pessoas e nos seus desejos de soluções rápidas e imediatistas. Somado a essa situação, eles apontam a falta de compromisso do poder público, que se mostra em situações como a da precariedade da educação nas comunidades e a corrupção do meio político. Por fim, pudemos visualizar como os MCs compreendem poder ter um papel na mudança da realidade à sua volta.

\section{REFERÊNCIAS}

BUDÓ, Marília de Nardin. A redução da maioridade penal na folha de s. Paulo: da razão à emoção. Revista Eletrônica do Curso de Direito da UFSM, v. ıo, p. 94-125, 2015.

CAVALCANTI, M. F. ; TANNUSS, R. W. Uma discussão sobre a redução da maioridade penal. In: VII Jornada Internacional de Políticas Públicas, 2015, São Luís. VII Jornada Internacional de Políticas Públicas - Para além da crise global: experiências e antecipações concretas, 2015.

DOTTO, H; MORAIS, L. X. A Redução Da Maioridade Penal E A Atividade Legislativa No Senado Federal. Revista Liberdades, vol. 25, 2018.

FAIRCLOUGH, Norman. Discurso e Mudança Social. Brasília: Editora UnB, 2016. Analysing Discourse: textual analysis for social research. London: Routledge, 2003.

LINS, R.; OLIVEIRA, L. A.; FIGUEIREDO FILHO, D. B. . A redução da maioridade penal diminui a violência? Evidências de um estudo comparado. Opinião Pública (UNICAMP. Impresso), v. 22, p. II8-139, 2016.

HALlidAY, M. A. K.; MATTHIESSEN, C. Introduction to Functional Grammar. 4ed. London: Arnold, 2014.

RESENDE, Viviane de Melo; RAMALHO, Viviane. Análise de discurso crítica. 2. Ed. São Paulo. Editora Contexto, 2011.

SOARES, G. A idade mínima penal e a redução do achismo. Correio Braziliense, 22 fev. 2007. VAN DIJK, T. Discurso e Poder. São Paulo: Contexto, 2008. 